\title{
EFFECT OF PENICILLIN ON GROUP A STREPTOCOCCI IN VIVO IN THE ABSENCE OF LEUCOCYTES ${ }^{1}$
}

\author{
By JAMES E. DARNELL, JR.,2 BARBARA B. PESCH, AND ROBERT J. GLASER
}

(From the Division of Immunology, Department of Internal Medicine, Washington University School of Medicine, St. Louis, Mo.)

(Submitted for publication March 8, 1955; accepted March 23, 1955)

Studies of penicillin action in vitro have indicated that, under given experimental conditions, the antibiotic is bactericidal rather than bacteriostatic (1-5), and it has been further demonstrated that it exerts its bactericidal effect on susceptible microorganisms only when they are actively metabolizing, a state indicated usually by rapid growth (6-9). Although there is also evidence that when it is administered in the initial phase of experimental infections due to susceptible organisms penicillin is bactericidal $(10,11)$, elucidation of its effect in vivo has been complicated by the participation of host cellular defenses which, under certain circumstances, may in themselves be extremely efficient (12). The recent description by Werner, Knight, and McDermott of a method by which bacteria can be localized in vivo in a cellfree milieu (13) suggested the means by which the effect of penicillin on group A streptococci, in the absence of leucocytes, could be assayed at various stages of growth in the peritoneal cavity of the rabbit.

\section{METHODS AND MATERIALS}

Preparation of agar disks. The techniques employed were patterned after those described by Werner, Knight, and McDermott (13). A 2 per cent suspension of nonnutrient agar (Difco Bactoagar) in distilled water at $\mathrm{pH}$ 7.8 was sterilized in flasks in the autoclave and stored at $2^{\circ} \mathrm{C}$. The disks were made by pouring melted agar, at $39^{\circ} \mathrm{C}$ to $41^{\circ} \mathrm{C}$, under aseptic precautions, into thinwalled cylindrical aluminum molds measuring $22 \mathrm{~mm}$. in diameter and 15 to $20 \mathrm{~mm}$. in height. The sterile cylinders were placed in petri dishes and a $1 \mathrm{ml}$. layer of agar introduced. The petri dish was then covered and cooled at $2^{\circ} \mathrm{C}$ for 15 minutes. The second layer, containing the inoculum in $0.2 \mathrm{ml}$. of agar, was poured onto the hardened first layer, care being taken to prevent any of the bacteria-containing suspension from reaching the wall of the mold; the desired result was easily achieved because the $0.2 \mathrm{ml}$. layer solidified almost immediately on con-

1 Supported by a grant from the Life Insurance Medical Research Fund.

2 Fourth year medical student when this work was done. tact with the hardened basal portion. Two $\mathrm{ml}$. of plain agar were added as a cover to complete the disk, and after the agar had hardened, the aluminum ring was removed.

Preparation of inoculum. In the experiments herein described, a single strain of group A streptococcus, S23 Burbank, was employed. The organism was obtained originally from Dr. Maclyn McCarty of the Rockefeller Institute for Medical Research; identical stock samples were prepared by concentrating cultures of the organism, grown in beef infusion broth with 10 per cent sheep serum and 0.5 per cent dextrose (BIB-SD), and storing $0.2 \mathrm{ml}$. aliquots at $-72^{\circ} \mathrm{C}$. For the various studies described, $5 \mathrm{ml}$. of BIB-SD at $\mathrm{pH} 7.8$ were inoculated with 2 loopfuls of rapidly thawed stock culture and incubated at $37^{\circ} \mathrm{C}$ for 16 hours, after which $0.5 \mathrm{ml}$. was transferred to $5 \mathrm{ml}$. of fresh BIB-SD and incubated for 4 hours. Tenfold dilutions were made in tryptose phosphate broth, and $1.0 \mathrm{ml}$. of the $10^{-5}$ dilution was added to $9.0 \mathrm{ml}$. of melted agar at $40^{\circ} \mathrm{C}$ and thoroughly mixed. The $0.2 \mathrm{ml}$. portion of this mixture, employed in the disk, contained 350 to 400 chains.

Implantation of disks. New Zealand rabbits, obtained from a single breeder, and free of demonstrable infection were used. The animals weighed 2.5 to $3.0 \mathrm{Kg}$., and were maintained under standard laboratory conditions. Preoperative preparation included careful depilatation of the abdomen over a rectangular area approximately $12 \times$ $8 \mathrm{~cm}$. ; this area was then scrubbed vigorously with hexachloroprene soap (pHisoderm (8). Laparotomy was performed under local anesthesia with 1 per cent procaine hydrochloride; aseptic technique was employed. A 6 to $8 \mathrm{~cm}$. midline incision was made, and the disks placed so that contact between their surfaces was prevented. It was possible to insert as many as six disks on either side of the peritoneal cavity without difficulty. After implantation was completed, the peritoneum and muscle layers were closed with a continuous silk suture and the skin with Michele clips.

Disks were removed through the same incision, and ground separately, without sand, in sterile mortars. In order to bring the final volume to $8.0 \mathrm{ml}$., $4.8 \mathrm{ml}$. of tryptose phosphate broth were added, and poured blood agar plates were made with $1 \mathrm{ml}$. aliquots of suitable tenfold dilutions of the ground disk suspensions for determination of the number of viable chains of streptococci.

Administration of penicillin. In all of the experiments, a standard dose of 30,000 units of aqueous procaine penicillin $G$ was employed and the drug was administered 
intramuscularly according to the schedules described in the following section.

When penicillin was administered prior to disk removal, 10 to 20 units of penicillinase (Schenley) were incorporated in the poured plates made from such disks; these amounts were in excess of those needed to inactivate the drug in the concentrations present.

Penicillin content of agar disks was determined at various intervals, including those instances in which prior observations indicated that viable bacteria persisted despite exposure to the antibiotic. Qualitative assays were performed by the serial dilution capillary tube method of Fleming (14). Disks were ground in a sterile mortar, and $4.8 \mathrm{ml}$. of tryptose phosphate broth were added, making a final volume of $8.0 \mathrm{ml}$. Aliquots of this suspension were used for the penicillin determinations.

\section{RESULTS}

General observations. Contamination of the peritoneal cavity by streptococci did not occur except in a single instance when a disk was inadvertently fractured during removal. Although a fibrin-leucocyte membrane formed about disks in approximately 24 hours, disk integrity was maintained, and leucocytes did not gain access to the agar. The latter findings confirm those of Werner, Knight, and McDermott (13).

Normal growth curve. After intraperitoneal implantation in disks, the streptococci entered the logarithmic phase of growth immediately, and continued to multiply at a maximal rate for eight hours (Figure 1), attesting to the prompt diffusion of essential nutrients from the host environment into the disk. Thereafter only a slight increase in bacterial population was noted, and a plateau was

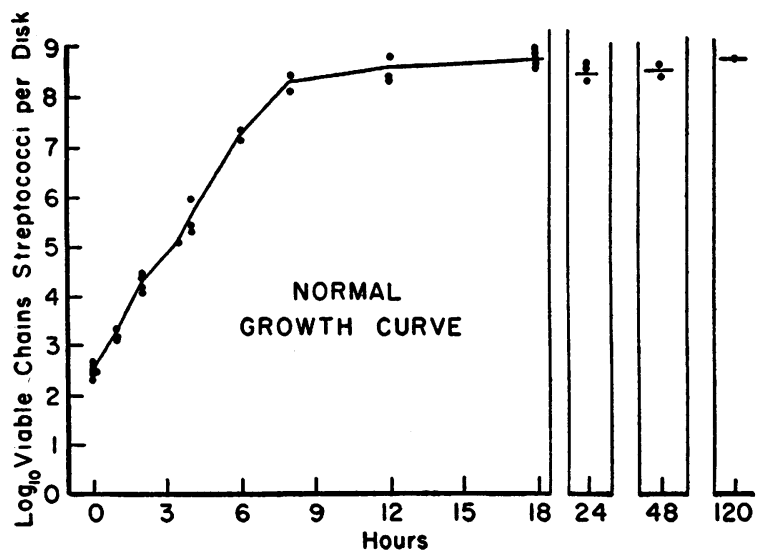

Fig. 1. Normal Growth Curve for Streptococcal Strain S23 Burbank WhEN IMplanted INTraperiTONEALLY IN DisKS

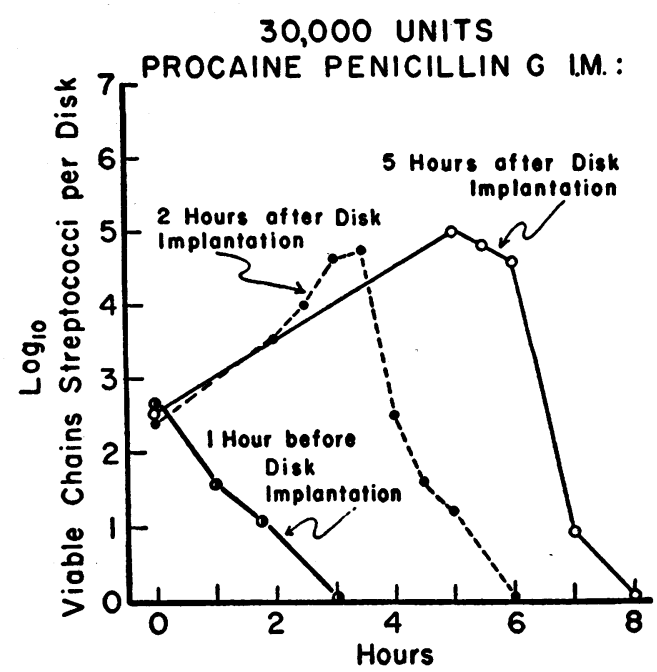

Fig. 2. Bactericidal Effect of Penicillin, Given BEFORE OR SOON AFTER Disk IMPlantation, ON StrepTOCOCCI

reached by eighteen hours. Little change in the bacterial count was noted for the next five days after which the viable organisms gradually diminished in number, and five weeks after implantation the disks were sterile. The growth curve for the strain employed was readily reproducible as is indicated by the fact that the multiple coordinates for any given time shown in Figure 1 represent observations made on disks from different animals.

Effect of single doses of penicillin. In various experiments single injections of penicillin were given rabbits prior to or at intervals after implantation of disks. It may be seen in Figures 2, 3, and 4 that three kinds of effects were noted after administration of single doses of the antibiotic. Thus when the bacteria were exposed to penicillin within five hours of disk implantation (Figure 2) sterilization was achieved in the ensuing four hours. On the other hand, when treatment was not instituted until 12 hours after the disks were introduced into the abdominal cavity (Figure 3 ) the bacterial population was affected as indicated by a decrease in the number of viable chains, but sterilization could not be attained. Finally, penicillin given 24 hours after disk implantation, after the streptococci had reached the plateau phase in their growth, failed to effect any reduction in the number of viable bacteria (Figure 4).

Effect of multiple doses of penicillin. In view of the fact that single large doses of penicillin 

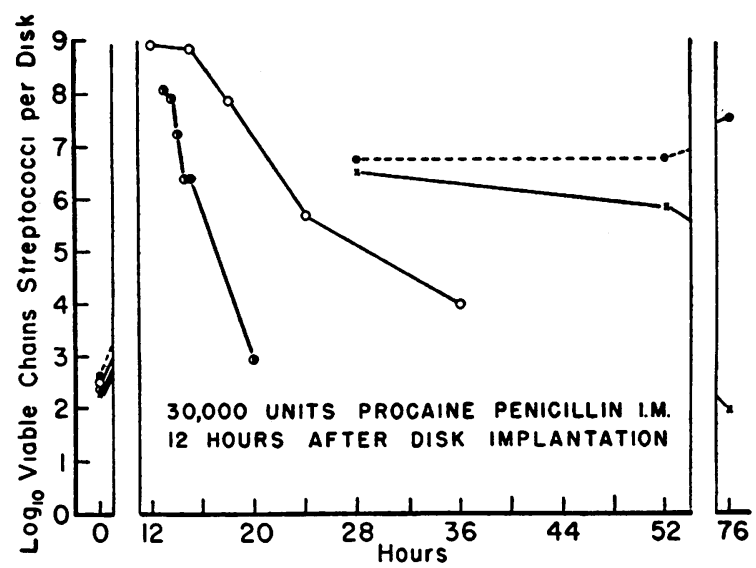

Fig. 3. Partial Killing of Streptococci by Penictllin Administered 12 Hours after Disk Implantation

Each curve represents a separate experiment.

failed to sterilize disks in which growth of streptococci had proceeded for 12 or more hours, it was thought desirable to ascertain the effect of multiple doses of penicillin under comparable conditions. In separate experiments, therefore, disks were placed intraperitoneally in three rabbits and penicillin was given 24,48 , and 72 hours later. Even this intensive therapeutic regimen failed to kill all of the streptococci (Figure 5), although there was apparently a significant decrease in the number of viable bacteria.

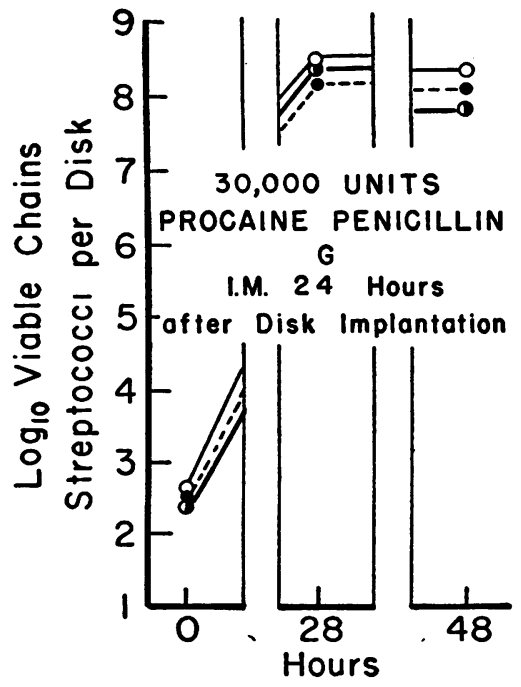

Fig. 4. Failure of Penicillin, Given 24 Hours after Disk Implantation, to Influence Viability of STREPTOCOCCI

Each curve represents a separate experiment.

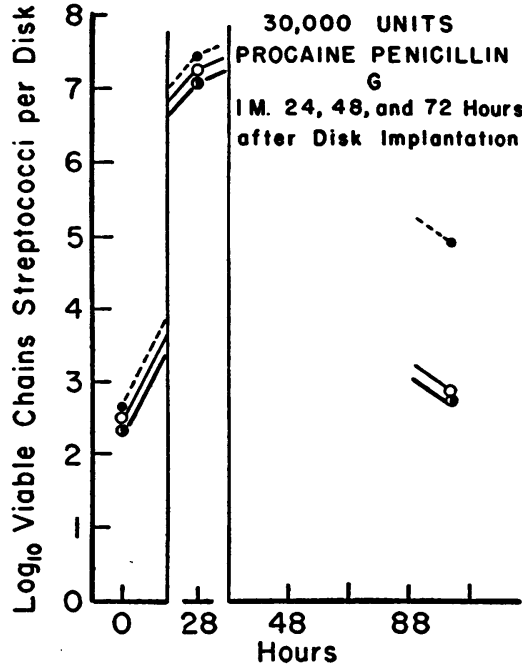

Fig. 5. Failure of Penicillin, When Given in Repeated Doses Beginning 24 Hours after Disk Implantation, to Effect Sterilization of the Foci

Each curve represents a separate experiment.

Penetration of penicillin into disks. The results of determination of penicillin content of disks at varying intervals after drug administration are given in Table $I$. They indicate that the failure of penicillin to kill organisms 12 or more hours after implantation was not due to impenetrability of the disk to the drug ; indeed, the amount of drug which diffused into the disk was of an order which would have been bactericidal for rapidly growing cultures of the organism employed in the experiments.

TABLE I

Penetration of Agar Disks by Penicillin

\begin{tabular}{ccc}
$\begin{array}{c}\text { Interval in Hours Between } \\
\text { Disk Implantation and } \\
\text { Penicillin Administration }\end{array}$ & $\begin{array}{c}\text { Interval in Hours } \\
\text { Between Penicillin } \\
\text { Adainistration and } \\
\text { Disk Assay }\end{array}$ & $\begin{array}{c}\text { Result of } \\
\text { Penicili in } \\
\text { Assay }\end{array}$ \\
\hline 2 & 2 & + \\
& 4 & + \\
& 6 & + \\
& 12 & + \\
\hline 12 & 24 & + \\
\hline 24 & 3 & + \\
& 6 & + \\
\hline & 4 & + \\
\hline
\end{tabular}

+ ind icates presence of, and 0 absence of penicillin in bacteriothe disk (voluie 3.2. $\mathrm{ml}$.) was diluted to a final volume of $8.0 \mathrm{ml}$. before the deterninations were made. 


\section{DISCUSSION}

The results of these experiments indicate that in vivo, in the absence of leucocytes, eradication of a penicillin-susceptible organism is achieved promptly when the drug is given during the period of logarithmic growth of the bacteria. As the maximum population density is approached, however, the bactericidal effect of penicillin becomes progressively less apparent and twenty-four hours after introduction of the inoculum, the streptococci exhibit no susceptibility to the action of the drug. Indeed, even repeated exposure to large amounts of penicillin fails to effect sterilization of the bacterial foci, despite the fact that penicillin diffuses into the disks in sufficient amounts to kill rapidly multiplying organisms. The findings thus confirm earlier in vitro (1-5) as well as in vivo observations $(10,11)$, and suggest that the favorable outcome usually obtained in the treatment of patients with group A streptococcal infections is due in considerable part to the host cellular defenses, participation of which was excluded in the studies herein described. It may also be inferred that the previously demonstrated inadequacy of short-term penicillin therapy $(15,16)$ results from persistence of resting streptococci in foci, such as abscesses, in which host defenses are hampered (17). It is well known that group A streptococci may be carried in the pharynx for long periods of time $(18,19)$, often in a metabolically altered state (20). That the organisms may be recovered from the excised tonsils of patients subjected to tonsillectomy, even when pharyngeal cultures have failed to reveal the presence of streptococci, has been repeatedly demonstrated $(21,22)$. It is of considerable importance that in some of these instances penicillin therapy had been given in the immediate pre-operative period $(23,24)$. Since most of the patients from whose tonsils streptococci were recovered had no clinical findings suggestive of pharyngitis it can be presumed that they were carriers of the organisms.

Since it has been postulated that in man persistence of streptococci may be of importance in the pathogenesis of rheumatic fever $(25,26)$, this study re-emphasizes the importance of early penicillin treatment of streptococcal infections (27). The fact that intensive penicillin therapy, in- stituted as late as nine days after the onset of streptococcal pharyngitis, usually prevents rheumatic fever (25) suggests that, in most instances, the combination of antibiotic action and of host defense mechanisms eliminates the organisms. It is possible, however, that the occasional failure of apparently adequate amounts of penicillin to prevent rheumatic fever $(25,28)$ may be due to survival of resting organisms in such tissues as the tonsil where host defenses may be ineffectual.

\section{SUMMARY}

When four-hour cultures of group A streptococci are incorporated in the center of agar disks and implanted in the peritoneal cavity of the rabbit, the organisms enter immediately the logarithmic phase of growth and continue to multiply at maximal rates for eight hours. Subsequently a plateau is reached and persists for five days. Large amounts of penicillin administered prior to or within five hours of implantation kill the bacteria promptly, but when given twelve hours or more after implantation, the drug fails to sterilize the foci. Although repeated administration decreases the bacterial count, some viable organisms persist.

The implications of these findings on the treatment and sequelae of streptococcal infection in man are discussed.

\section{REFERENCES}

1. Hobby, G. L., Meyer, K., and Chaffee, E., Activity of penicillin in vitro. Proc. Soc. Exper. Biol. \& Med., 1942, 50, 277.

2. Rammelkamp, C. H., and Keefer, C. S., Penicillin: Its antibacterial effect in whole blood and serum for the hemolytic streptococcus and staphylococcus aureus. J. Clin. Invest., 1943, 22, 649.

3. Eriksen, K. R., Some studies on the lytic action of penicillin on staphylococci and pneumococci. Acta path. et microbiol. Scandinav., 1946, 23, 221.

4. Eriksen, K. R., Studies on the action of penicillin on some rod-shaped, penicillinase-producing bacteria. Acta path. et microbiol. Scandinav., 1946, 23, 489.

5. Parker, R. F., and Marsh, H. C., The action of penicillin on staphylococcus. J. Bact., 1946, 51, 181.

6. Hobby, G. L., Meyer, K., and Chaffee, E., Observations on the mechanism of action of penicillin. Proc. Soc. Exper. Biol. \& Med., 1942, 50, 281.

7. Hobby, G. L., and Dawson, M. H., Effect of rate of growth of bacteria on action of penicillin. Proc. Soc. Exper. Biol. \& Med., 1944, 56, 181. 
8. Lee, S. W., Foley, E. J., and Epstein, J. A., Mode of action of penicillin. I. Bacterial growth and penicillin activity-Staphylococcus aureus FDA. J. Bact., 1944, 48, 393.

9. Todd, E. W., Bacteriolytic action of penicillin. Lancet, 1945, 1, 74.

10. Jawetz, E., Dynamics of the action of penicillin in experimental animals; observations on mice. Arch. Int. Med., 1946, 77, 1.

11. Eagle, H., Experimental approach to the problem of treatment failure with penicillin. I. Group A streptococcal infection in mice. Am. J. Med., 1952, $13,389$.

12. Wood, W. B., Jr., Studies on the cellular immunology of acute bacterial infections. Harvey Lect., 19511952, 47, 72.

13. Werner, C. A., Knight, V., and McDermott, W., Studies of microbial populations artificially localized in vivo. I. Multiplication of bacteria and distribution of drugs in agar loci. J. Clin. Invest., 1954, 33, 742.

14. Fleming, A., Micro-methods of estimating penicillin in blood serum and other fluids. Am. J. Clin. Path., 1945, 15, 1.

15. Spink, W. W., Rantz, L. A., Boisvert, P. J., and Coggeshall, H., Sulfadiazine and penicillin for hemolytic streptococcus infections of the upper respiratory tract; an evaluation in tonsillitis, nasopharyngitis, and scarlet fever. Arch. Int. Med., 1946, 77, 260.

16. Plummer, N., Duerschner, D. R., Warren, H. D., Rogliano, F. T., and Sloan, R. A., Penicillin therapy in hemolytic streptococcic pharyngitis and tonsillitis. J.A.M.A., 1945, 127, 369.

17. Smith, M. R., and Wood, W. B., Jr., Personal communication.

18. Rantz, L. A., The Prevention of Rheumatic Fever. Springfield, Ill., Charles C Thomas, 1952, p. 20.

19. Lemon, H. M., The nasal carrier of beta-hemolytic streptococci. New England J. Med., 1947, 237, 988.
20. Rothbard, S., and Watson, R. F., Variation occurring in group A streptococci during human infection; progressive loss of $\mathrm{M}$-substance correlated with increasing susceptibility to bacteriostasis. J. Exper. Med., 1948, 87, 521.

21. Rantz, L. A., The hemolytic streptococci. Studies on the carrier state in the San Francisco area, with notes on the methods of isolation and serological classification of these organisms. J. Infect. Dis., 1941, 69, 248.

22. Nelson, H. G., Studies on rheumatic fever. Observations on tonsillar carriers of hemolytic streptococci; the effect of tonsillectomy and the administration of penicillin on rheumatic and nonrheumatic fever patients. J. Infect. Dis., 1948, 83, 138.

23. György, E., and Székely, A., Absorption and effect of penicillin injected into the tonsils on the bacterial flora of tonsils. Acta oto-laryng., 1951, 39, 62.

24. Lund, E., and Everberg, G., Preoperative penicillin therapy in tonsillectomy. Acta oto-laryng., 1952, 42, 125.

25. Catanzaro, F. J., Stetson, C. A., Morris, A. J., Chamovitz, R., Rammelkamp, C. H., Jr., Stoltzer, B. L., and Perry, W. D., The role of the streptococcus in the pathogenesis of rheumatic fever. Am. J. Med., 1954, 17, 749.

26. Rammelkamp, C. H., Jr., The natural history of streptococcal infections. Bull. New York Acad. Med., 1955, 31, 103.

27. Massell, B. F., Sturgis, G. P., Knobloch, J. D., Streeper, R. B., Hall, T. N., and Norcross, P., Prevention of rheumatic fever by prompt penicillin therapy of hemolytic streptococcic respiratory infections. J.A.M.A., 1951, 146, 1469.

28. Wannamaker, L. W., Rammelkamp, C. H., Jr., Denny, F. W., Brink, W. R., Houser, H. B., Hahn, E. O., and Dingle, J. H., Prophylaxis of acute rheumatic fever by treatment of the preceding streptococcal infection with various amounts of depot penicillin. Am. J. Med., 1951, 10, 673.

\section{ERRATUM}

In the article "The Effect of Acute Arteriovenous Fistula on Renal Functions," by James G. Hilton, Donald M. Kanter, David R. Hays, Edward H. Bowen, James R. Golub, John H. Keating, and René Wégria, J. Clin. Invest., 1955, 34, 732, left column, p. 735, line 18 ". . . occurred an increase in the sodium excretion while" should read ". . . occurred a decrease in the sodium excretion while"; line 20 ". . . upon closing the fistula (experiments 7 and 8) . . ." should read ". . . upon closing the fistula (experiments 4 and 8) ..." 